\title{
Dietas de baixa proteína no desempenho de frangos criados em diferentes temperaturas
}

\author{
Daniel Emygdio de Faria Filho(1), Paulo Sérgio Rosa(1), Denise Fontana Figueiredo(1), Fabiano Dahlke(1), \\ Marcos Macari( ${ }^{(1)}$ e Renato Luis Furlan ${ }^{(1)}$
}

\begin{abstract}
(1)Universidade Estadual Paulista, Fac. de Ciências Agrárias e Veterinárias, Dep. de Morfologia e Fisiologia Animal, Via de Acesso Professor Paulo Donato Castellane, s/no, CEP 14884-900 Jaboticabal SP. E-mail: dfaria@fcav.unesp.br, prosa2@fcav.unesp.br, deniseffigueiredo@yahoo.com.br, fdahlke@fcav.unesp.br, macari@fcav.unesp.br, rlfurlan@fcav.unesp.br
\end{abstract}

Resumo - O objetivo deste trabalho foi avaliar o desempenho de frangos, entre 42 e 49 dias, alimentados com dietas de baixa proteína e criados em diferentes temperaturas. Foram utilizados 360 frangos, machos, Cobb-500, distribuídos em um delineamento inteiramente ao acaso em esquema fatorial 3x3 (temperatura ambiente de 20, 25 e $32^{\circ} \mathrm{C}$ e dietas com teores de proteína bruta de 18,0, 16,5 e 15,0\%), com quatro repetições de dez aves cada. As dietas com baixa proteína prejudicaram o desempenho e a eficiência de retenção de nitrogênio dos frangos criados em $32^{\circ} \mathrm{C}$. Os rendimentos de carcaça e de coxa e sobrecoxa foram maiores nas aves criadas a $32^{\circ} \mathrm{C}$. Os demais cortes e a deposição de gordura abdominal não foram alterados. O estresse por calor reduziu o teor de proteína e aumentou o de gordura na coxa e sobrecoxa, ao passo que os teores protéicos não alteraram a composição bromatológica dos cortes. A utilização de dietas com baixa proteína piora o desempenho de frangos, de 42 a 49 dias, criados em estresse por calor. No entanto, essas dietas podem ser utilizadas em frangos criados em 20 ou $25^{\circ} \mathrm{C}$, pois não alteram o desempenho, a qualidade da carcaça e diminuem a excreção de nitrogênio.

Termos para indexação: aminoácidos, nitrogênio, carcaça, estresse.

\section{Low-protein diets on broilers performance reared under different temperatures}

\begin{abstract}
The objective of this work was to evaluate broilers performance, from 42 to 49 days, fed on lowprotein diet and reared under different temperatures. Three hundred and sixty male broilers from Cobb-500 strain were randomly housed in a $3 \times 3$ factorial arrangement (environmental temperature of 20,25 and $32^{\circ} \mathrm{C}$ and crude protein levels of 18.0, 16.5 and 15.0\%) with four replicates of ten birds each. Performance and efficiency of nitrogen retention were impaired in broilers fed on low-protein diets and reared under temperature of $32^{\circ} \mathrm{C}$. Carcass, as well as thigh and drumstick increased in birds reared at hot temperature yield, however other parts yield, and abdominal fat deposition were not altered by the studied factors. Drumstick and thigh protein composition decreased in broilers reared under heat stress, while fat composition increased. Protein levels did not affect carcass composition. Low-protein diet impairs broiler performance in heat-exposed broilers from 42 to 49 days. However, broilers can be fed on low-protein diets under temperatures of 20 or $25^{\circ} \mathrm{C}$, because these temperatures did not affect broilers performance, carcass quality, and they promoted lower nitrogen excretion.
\end{abstract}

Index terms: amino acids, nitrogen, carcass, stress.

\section{Introdução}

O estresse pelo calor é um dos principais fatores que prejudicam as características zootécnicas dos frangos de corte, o que tem resultado em aumento dos estudos em técnicas que possam amenizar seus efeitos. Uma dessas práticas é a redução da proteína bruta dietética pelo uso do conceito de proteína ideal, uma vez que o incremento calórico gerado pela proteína é maior que o dos carboidratos e gorduras (Musharaf \& Latshaw, 1999).
Entretanto, os resultados alcançados com a redução da proteína em altas temperaturas não têm sido consistentes. Cheng et al. (1999) relataram que diminuir a proteína bruta da dieta pode melhorar o desempenho das aves criadas em ambiente quente. No entanto, Alleman \& Leclercq (1997) e Temim et al. (2000) demonstraram que esse procedimento acentuou os efeitos prejudiciais do estresse por calor sobre o desempenho dos frangos de corte.

Existem dois outros pontos que devem ser considerados na definição do melhor teor protéico em dietas de 
frangos. O primeiro deles refere-se à menor excreção de nitrogênio, utilizando dietas com baixa proteína, que além de reduzirem o consumo, melhoram a eficiência na utilização do nitrogênio pelas aves (Aletor et al., 2000). Entretanto, existem poucas pesquisas que consideram a influência da temperatura de criação das aves sobre a emissão de nitrogênio para o ambiente.

O segundo ponto refere-se à qualidade da carcaça. É crescente o interesse da indústria por práticas que resultem em maior rendimento de carcaça e de cortes nobres em frangos de corte, especialmente de carne de peito. Também se busca a redução da deposição de gordura na carcaça dos frangos.

A temperatura ambiente de criação e os teores de proteína bruta da dieta podem influenciar a qualidade da carcaça das aves. Aïn Baziz et al. (1996) verificaram que frangos criados em temperatura elevada apresentam menor rendimento de peito e maior deposição de gordura na carcaça. Araújo (2001) encontrou menor rendimento de carcaça em frangos alimentados com dietas com baixa proteína bruta, de 21 a 42 dias. Por sua vez, trabalhos sobre a composição bromatológica dos cortes comerciais (peito, coxa e sobrecoxa e asa), em virtude da temperatura de criação e dos teores de proteína dietética, são escassos.

O objetivo deste trabalho foi avaliar o efeito de dietas com baixa proteína, formuladas mediante o conceito de proteína ideal, sobre o desempenho, a qualidade de carcaça e o balanço de nitrogênio de frangos, entre 42 e 49 dias, criados em diferentes temperaturas.

\section{Material e Métodos}

No período de 1 a 42 dias, as aves receberam dietas de acordo com o descrito na Tabela 1 e foram criadas em temperaturas termoneutras: $32,1 \pm 2,4^{\circ} \mathrm{C}$ ( 1 a 7 dias), $28,2 \pm 1,6^{\circ} \mathrm{C}$ (8 a 14 dias), $26,2 \pm 2,6^{\circ} \mathrm{C}$ (15 a 21 dias) e $23,8 \pm 2,2^{\circ} \mathrm{C}$ (22 a 42 dias). No $42^{\circ}$ dia, foram montadas unidades experimentais com aves pesando em média $2.588,1 \pm 37,8$ g, utilizando 360 frangos, machos, Cobb500, distribuídos em um delineamento inteiramente ao acaso em esquema fatorial $3 \times 3$. Os fatores consistiram em temperatura ambiente $\left(20,25\right.$ e $\left.32^{\circ} \mathrm{C}\right)$ e teores de proteína bruta na dieta $(18,0,16,5$ e 15,0\%), totalizando nove tratamentos com quatro repetições de dez aves cada. A ração e a água foram fornecidas à vontade e as aves foram manejadas convencionalmente.

As temperaturas nas câmaras climatizadas durante o período experimental (42 a 49 dias) foram de 20,0 $\pm 2,6$,
Tabela 1. Composição centesimal em ingredientes, energia e nutrientes das dietas pré-experimentais (inicial de 1 a 21 dias e crescimento de 22 a 42 dias) e experimentais no período de 42 a 49 dias.

\begin{tabular}{|c|c|c|c|c|c|}
\hline \multirow[t]{2}{*}{ Ingrediente } & \multicolumn{2}{|c|}{$\begin{array}{c}\text { Dieta pré- } \\
\text { experimental }\end{array}$} & \multicolumn{3}{|c|}{$\begin{array}{c}\text { Dieta } \\
\text { experimental } \\
\end{array}$} \\
\hline & Inicial & $\begin{array}{l}\text { Cresci- } \\
\text { mento }\end{array}$ & $18,0 \%^{(1)}$ & $16,5 \%$ & $15,0 \%$ \\
\hline Milho & 54,72 & 57,58 & 63,27 & 68,77 & 75,03 \\
\hline Farelo de soja & 36,62 & 32,87 & 27,44 & 22,16 & 15,98 \\
\hline Óleo de soja & 4,76 & 5,90 & 5,74 & 4,75 & 3,59 \\
\hline Fosfato bicálcico & 1,77 & 1,70 & 1,76 & 1,81 & 1,87 \\
\hline Calcário calcítico & 1,08 & 0,97 & 0,97 & 0,97 & 0,97 \\
\hline Sal comum & 0,45 & 0,45 & 0,41 & 0,25 & 0,06 \\
\hline Bicarbonato de sódio & - & - & - & 0,24 & 0,51 \\
\hline Cloreto de potássio & - & - & - & 0,15 & 0,32 \\
\hline Cloreto de colina $60 \%$ & 0,10 & 0,09 & 0,08 & 0,10 & 0,12 \\
\hline Coxistac $12 \%$ & 0,05 & 0,05 & - & - & - \\
\hline Bacitracina de zinco $15 \%$ & 0,03 & 0,03 & - & - & - \\
\hline Suplemento $^{(2)}$ & 0,10 & 0,10 & 0,10 & 0,10 & 0,10 \\
\hline L-Lisina & - & - & - & 0,17 & 0,37 \\
\hline DL-Metionina & 0,32 & 0,26 & 0,23 & 0,23 & 0,28 \\
\hline L-Treonina & - & - & - & 0,07 & 0,16 \\
\hline L-Triptofano & - & - & - & 0,03 & 0,05 \\
\hline L-Valina & - & - & - & 0,09 & 0,19 \\
\hline L-Arginina & - & - & - & 0,04 & 0,21 \\
\hline L-Isoleucina & - & - & - & 0,07 & 0,17 \\
\hline \multirow[t]{2}{*}{ Total } & 100,00 & 100,00 & 100,00 & 100,00 & 100,00 \\
\hline & \multicolumn{5}{|c|}{$\begin{array}{c}\text { Composição calculada } \\
\text { Energia e nutrientes }\end{array}$} \\
\hline Energia $\left(\mathrm{kcal} \mathrm{kg}^{-1}\right)^{(3)}$ & 3.080 & 3.190 & 3.245 & 3.245 & 3.245 \\
\hline Proteína bruta (\%) & 21,50 & 20,00 & 18,00 & 16,50 & 15,00 \\
\hline Cálcio (\%) & 0,97 & 0,90 & 0,90 & 0,90 & 0,90 \\
\hline Fósforo disponível (\%) & 0,47 & 0,45 & 0,45 & 0,45 & 0,45 \\
\hline Potássio (\%) & 0,90 & 0,83 & 0,74 & 0,74 & 0,74 \\
\hline Sódio (\%) & 0,20 & 0,20 & 0,18 & 0,18 & 0,18 \\
\hline Cloro (\%) & 0,35 & 0,35 & 0,31 & 0,31 & 0,31 \\
\hline Equilíbrio (meq kg $\left.{ }^{-1}\right)^{(4)}$ & 219 & 201 & 180 & 180 & 180 \\
\hline \multirow[t]{2}{*}{ Colina (ppm) } & 1.962 & 1.815 & 1.640 & 1.640 & 1.640 \\
\hline & \multicolumn{5}{|c|}{ Aminoácidos digestíveis (\%) } \\
\hline Lisina & 1,13 & 1,03 & 0,89 & 0,89 & 0,89 \\
\hline Metionina+cistina & 0,87 & 0,77 & 0,71 & 0,67 & 0,67 \\
\hline Treonina & 0,76 & 0,71 & 0,63 & 0,62 & 0,62 \\
\hline Triptofano & 0,17 & 0,16 & 0,14 & 0,15 & 0,15 \\
\hline Valina & 0,83 & 0,77 & 0,68 & 0,69 & 0,69 \\
\hline Arginina & 1,27 & 1,17 & 1,02 & 0,93 & 0,93 \\
\hline Isoleucina & 0,77 & 0,71 & 0,62 & 0,60 & 0,60 \\
\hline Leucina & 1,65 & 1,55 & 1,42 & 1,28 & 1,13 \\
\hline Histidina & 0,52 & 0,49 & 0,44 & 0,40 & 0,35 \\
\hline Fenilalanina+tirosina & 1,51 & 1,40 & 1,27 & 1,14 & 0,98 \\
\hline
\end{tabular}

${ }^{(1)}$ Controle. ${ }^{(2)}$ Suplemento de vitaminas/minerais (quantidade por $\mathrm{kg}$ de ração): vitamina $\mathrm{A}, 1.500 \mathrm{UI}$; vitamina D3, $500 \mathrm{UI}$; vitamina E, $20 \mathrm{mg}$; vitamina $\mathrm{K}, 0,5 \mathrm{mg}$; vitamina $\mathrm{B} 1,2 \mathrm{mg}$; vitamina $\mathrm{B} 2$, 6,6 mg; vitamina B12, $20 \mu \mathrm{g}$; ácido fólico, 0,1 mg; ácido pantotênico, $10 \mathrm{mg}$; niacina, $100 \mathrm{mg}$; antioxidante, $125 \mathrm{mg}$; cobre, $10 \mathrm{mg}$; ferro, $50 \mathrm{mg}$; iodo, 1,4 mg; manganês, $88 \mathrm{mg}$; selênio, 0,3 mg; zinco, $100 \mathrm{mg}$. (3)Energia metabolizável. (4)Equilíbrio eletrolítico. 
$25,1 \pm 2,8$ e $32,2 \pm 2,4^{\circ} \mathrm{C}$, com umidade relativa do ar de $64,5 \pm 14,6,61,2 \pm 13,9$ e $50,4 \pm 12,6 \%$, respectivamente. Realizou-se o aquecimento por lâmpadas de infravermelho e o resfriamento por monoblocos refrigeradores, controlado por termostatos.

O milho e o farelo de soja foram analisados quanto aos teores de proteína bruta (Micro-Kjeldahl) e aminoácidos (por método cromatográfico) (Association of Official Analytical Chemists, 1984). As dietas com baixa proteína foram formuladas pelo conceito de proteína ideal, em que a exigência dos aminoácidos essenciais digestíveis foi expressa como uma porcentagem da lisina digestível (Baker \& Han, 1994): metionina+cistina $75 \%$, treonina $70 \%$, triptofano $17 \%$, valina $77 \%$, arginina $105 \%$ e isoleucina $67 \%$ (Tabela 1).

As variáveis zootécnicas, avaliadas nos frangos de 42 a 49 dias, foram: o consumo de ração, o ganho de peso e a conversão alimentar (consumo de ração/ganho de peso). Os rendimentos de carcaça, peito, coxa e sobrecoxa e asa, além da deposição de gordura abdominal, foram avaliados aos 49 dias, em duas aves por parcela. Os cortes comerciais foram feitos por uma única pessoa treinada. O rendimento de carcaça e a gordura abdominal foram expressos em relação ao peso vivo, e as demais características em relação ao peso da carcaça com pés e cabeça. A matéria seca, extrato etéreo, proteína bruta e matéria mineral (Association of Official Analytical Chemists, 1984) foram analisadas, nos cortes de peito, coxa e sobrecoxa e asa.

A ingestão de nitrogênio foi calculada multiplicando-se o consumo de ração pelo teor de nitrogênio da ração. A fim de avaliar a retenção de nitrogênio, foi realizado um abate referencial de dez aves no $42^{\circ} \mathrm{O}$ dia, e outro de duas aves por parcela no 49o dia. Todas elas foram moídas inteiras, com penas, sangue e vísceras, e o teor de nitrogênio determinado. A retenção de nitrogênio foi calculada pela diferença de nitrogênio aos 49 e 42 dias. A eficiência de retenção de nitrogênio foi obtida pela fórmula: (nitrogênio retido/nitrogênio ingerido)100. A excreção de nitrogênio foi estimada subtraindo-se o nitrogênio ingerido do retido. O teor de nitrogênio das carcaças e das dietas foi determinado pelo método de Micro-Kjeldahl (Association of Official Analytical Chemists, 1984).

Os dados foram submetidos à análise de variância por meio do procedimento General Linear Model (GLM) do SAS Institute (2002) e no caso de diferença significativa, as médias foram comparadas pelo teste de Tukey a $5 \%$ de probabilidade.

\section{Resultados e Discussão}

A temperatura de criação e os níveis de proteína não interagiram significativamente sobre o consumo de ração (Tabela 2). Com o aumento da temperatura ambiente ocorreu diminuição no consumo de ração (1.444 g, $20^{\circ} \mathrm{C} ; 1.266 \mathrm{~g}, 25^{\circ} \mathrm{C} ; 1.036 \mathrm{~g}, 32^{\circ} \mathrm{C}$ ), uma vez que, quanto maior o consumo de ração, maior a produção de calor (Koh \& Macleod, 1999). Os teores de proteína bruta não influenciaram o consumo de ração (1.262, 1.226 e 1.258 g para $18,0,16,5$, e $15,0 \%$ de proteína bruta, respectivamente), o que é explicado pelo bom balanceamento de aminoácidos das dietas com baixo teor protéico, que foram formuladas pelo conceito de proteína ideal (Gonzales, 2002).

Na Tabela 2, encontra-se o desdobramento da interação entre a temperatura ambiente e o teor protéico, no ganho de peso e na conversão alimentar. As aves alimentadas com baixa proteína bruta apresentaram pior ganho de peso e conversão alimentar quando criadas em temperatura ambiente de $32^{\circ} \mathrm{C}$, no entanto, a redução protéica não alterou essas variáveis em frangos criados em temperatura ambiente de 20 ou $25^{\circ} \mathrm{C}$. Esses resultados concordam com Alleman \& Leclercq (1997) e Faria Filho (2003), que verificaram que a redução

Tabela 2. Desdobramento da interação entre temperatura ambiente e teor protéico, no consumo de ração, ganho de peso e na conversão alimentar de frangos de corte de 42 a 49 dias de idade $^{(1)}$.

\begin{tabular}{lcccc}
\hline Proteína bruta (\%) & \multicolumn{3}{c}{ Temperatura ambiente $\left({ }^{\circ} \mathrm{C}\right)$} & Média \\
\cline { 2 - 4 } & 20 & 25 & 32 \\
\hline \multicolumn{5}{c}{ Consumo de ração $(\mathrm{g})$} \\
18,0 & 1.429 & 1.255 & 1.104 & 1.262 \\
16,5 & 1.464 & 1.243 & 973 & 1.226 \\
15,0 & 1.440 & 1.302 & 1.032 & 1.258 \\
\hline Média & $1.444 \mathrm{~A}$ & $1.266 \mathrm{~B}$ & $1.036 \mathrm{C}$ \\
\hline \multicolumn{5}{c}{ Ganho de peso $(\mathrm{g})$} \\
18,0 & $653 \mathrm{aA}$ & $496 \mathrm{aB}$ & $348 \mathrm{aC}$ & 499 \\
16,5 & $673 \mathrm{aA}$ & $478 \mathrm{aB}$ & $232 \mathrm{abC}$ & 461 \\
15,0 & $679 \mathrm{aA}$ & $523 \mathrm{aB}$ & $191 \mathrm{bC}$ & 464 \\
\hline Média & 668 & 499 \\
\hline \multicolumn{5}{c}{ Conversão alimentar $\left(\mathrm{g} \mathrm{g} \mathrm{g}^{-1}\right)$} \\
18,0 & $2,191 \mathrm{aA}$ & $2,555 \mathrm{aA}$ & $3,179 \mathrm{cB}$ & 2,642 \\
16,5 & $2,174 \mathrm{aA}$ & $2,604 \mathrm{aA}$ & $4,512 \mathrm{bB}$ & 3,097 \\
15,0 & $2,122 \mathrm{aB}$ & $2,496 \mathrm{aAB}$ & $5,520 \mathrm{aA}$ & 3,379 \\
\hline Média & 2,162 & 2,551 & 4,404 \\
\hline
\end{tabular}

${ }^{(1)}$ Médias seguidas de letras diferentes, maiúsculas nas linhas e minúsculas nas colunas, diferem entre si pelo teste de Tukey a 5\% de probabilidade; os coeficientes de variação para consumo de ração, ganho de peso e conversão alimentar foram de 8,8, 11,6, 10,7 e 24,4\%, respectivamente. 
protéica acentuou os efeitos do estresse por calor sobre o desempenho dos frangos de corte de 21 a 42 dias. Esses resultados estão relacionados ao baixo consumo de ração das aves criadas em temperatura ambiente de $32^{\circ} \mathrm{C}$, que reduziu o consumo de energia e nutrientes. Além disso, Nieto et al. (1997) mostraram que dietas com baixa proteína bruta aumentaram a produção de calor, resultando em maior exigência de energia para mantença e reduzindo a eficiência de utilização da energia metabolizável para acréscimo de proteína.

Temim et al. (2000) verificaram que frangos que receberam alta proteína bruta (25\%), em temperatura elevada $\left(32^{\circ} \mathrm{C}\right)$, não apresentaram elevação no turnover muscular (síntese protéica e proteólise). Assim, considerando que a produção de calor é positivamente correlacionada com a síntese de proteína corporal (Macleod, 1997), a utilização de dietas com alta proteína bruta, em $32^{\circ} \mathrm{C}$, não alterou a produção de calor.

A temperatura de criação e o teor protéico da ração não interagiram significativamente quanto ao rendimento (Tabela 3) e à composição bromatológica (Tabela 4) dos cortes comerciais. Foi observado que a temperatura ambiente não alterou os rendimentos de peito e asa e o porcentual de gordura abdominal (Tabela 3). No entanto, Faria Filho (2003) verificou redução do rendimento de peito, aos 42 dias, em frangos submetidos a três semanas de estresse por calor. Já os rendimentos de carcaça e de coxa e sobrecoxa foram maiores em aves criadas em temperatura ambiente de $32^{\circ} \mathrm{C}$. Entretanto, os maiores rendimentos de carcaça e de coxa e sobrecoxa observados em aves criadas em temperatura elevada não justificam os piores ganho de peso e conversão alimentar.

Tabela 3. Rendimento de carcaça, de peito, de coxa e sobrecoxa (pernas), de asa e porcentagem de gordura abdominal de frangos de corte aos 49 dias de idade.

\begin{tabular}{|c|c|c|c|c|c|c|c|}
\hline \multirow[t]{2}{*}{ Parâmetro (\%) ${ }^{(1)}$} & \multicolumn{3}{|c|}{$\begin{array}{c}\text { Temperatura } \\
\text { ambiente }\left({ }^{\circ} \mathrm{C}\right)^{(2)}\end{array}$} & \multicolumn{3}{|c|}{$\begin{array}{c}\text { Proteína bruta } \\
(\%)\end{array}$} & \multirow[t]{2}{*}{$\begin{array}{l}\mathrm{CV} \\
(\%)\end{array}$} \\
\hline & 20 & 25 & 32 & 18,0 & 16,5 & 15,0 & \\
\hline Carc & $83,8 b$ & $84,4 a b$ & $85,0 \mathrm{a}$ & 84,2 & 84,4 & 84,6 & \\
\hline Peit & 29,6 & 29,5 & 29,1 & 29,6 & 29,2 & 29,3 & \\
\hline Pern & $29,5 \mathrm{~b}$ & $29,5 b$ & 30, & 29,7 & 29,8 & 30,0 & \\
\hline & & & 9 & 9,7 & 9,6 & 9,5 & \\
\hline Gordura abdominal & 1,8 & 1,7 & 1,7 & 1,7 & 1,7 & 1,7 & 18 \\
\hline
\end{tabular}

(1)O rendimento de carcaça e a gordura abdominal foram expressos em relação ao peso vivo e as demais características em relação ao peso da carcaça com pés e cabeça. ${ }^{(2)}$ Médias seguidas de letras diferentes na mesma linha, dentro de cada fator, diferem entre si pelo teste de Tukey a $5 \%$ de probabilidade.
As dietas com baixa proteína bruta não influenciaram o rendimento de carcaça dos cortes comerciais e a deposição de gordura abdominal (Tabela 3). Resultados semelhantes foram obtidos por Araújo (2001), que não encontrou alteração quanto ao rendimento de cortes comerciais e de gordura abdominal ao variar o teor protéico de 19,5 para 15,0\%, no período de 43 a 49 dias. Em um período de três semanas de alimentação, Faria Filho (2003) verificou aumento da gordura abdominal em frangos que receberam baixa proteína bruta.

As proteínas são fundamentais no aspecto nutricional e metabólico para o frango de corte, pois estão relacionadas a processos do organismo, como a formação dos tecidos estruturais (músculo). Por exemplo, nos animais em crescimento, a deposição protéica nos músculos esqueléticos contribui com cerca de $65 \%$ de toda a proteína depositada diariamente (Macari et al., 2002). Entretanto, o turnover (síntese e degradação) protéico do músculo esquelético pode ser afetado pelo estado nutricional (Nieto et al., 1994) e idade das aves (Tesseraud et al., 1996).

As análises revelaram que a temperatura ambiente não influenciou a composição bromatológica (matéria seca, proteína bruta, extrato etéreo e matéria mineral) do peito e da asa (Tabela 4). No entanto, frangos criados em temperatura ambiente de $32^{\circ} \mathrm{C}$ apresentaram maior teor de gordura e matéria seca na coxa e sobrecoxa

Tabela 4. Matéria seca (MS, \%), proteína bruta (PB, \%MS), extrato etéreo (EE, \%MS) e matéria mineral (MM, \%MS) do peito, da coxa e sobrecoxa (pernas) e da asa de frangos de corte aos 49 dias de idade ${ }^{(1)}$.

\begin{tabular}{|c|c|c|c|c|c|c|c|c|}
\hline \multicolumn{2}{|c|}{$\begin{array}{l}\text { Parâmetro } \\
(\%)\end{array}$} & \multicolumn{3}{|c|}{$\begin{array}{c}\text { Temperatura ambiente } \\
\left({ }^{\circ} \mathrm{C}\right)\end{array}$} & \multicolumn{3}{|c|}{ Proteína bruta (\%) } & \multirow[t]{2}{*}{$\begin{array}{l}\mathrm{CV} \\
(\%)\end{array}$} \\
\hline & & 20 & 25 & 32 & 18,0 & 16,5 & 15,0 & \\
\hline \multirow[t]{4}{*}{ Peito } & MS & 29,6 & 29,6 & 29,8 & 29,7 & 29,6 & 29,7 & 1,2 \\
\hline & PB & 72,5 & 72,6 & 72,5 & 72,7 & 72,6 & 72,3 & 1,8 \\
\hline & $\mathrm{EE}$ & 21,1 & 21,2 & 21,4 & 21,1 & 21,2 & 21,5 & 2,4 \\
\hline & MM & 6,4 & 6,2 & 6,2 & 6,2 & 6,2 & 6,2 & 3,1 \\
\hline \multirow[t]{4}{*}{ Pernas } & MS & $33,0 \mathrm{~b}$ & $33,1 b$ & $33,5 \mathrm{a}$ & 33,1 & 33,2 & 33,2 & 1,3 \\
\hline & PB & $50,5 \mathrm{a}$ & $50,5 \mathrm{a}$ & $49,1 \mathrm{~b}$ & 50,1 & 49,9 & 50,0 & 2,1 \\
\hline & EE & $37,4 b$ & $37,8 \mathrm{~b}$ & $39,7 \mathrm{a}$ & 38,0 & 38,0 & 38,4 & 1,6 \\
\hline & MM & 12,2 & 11,7 & 11,3 & 11,9 & 12,1 & 11,6 & 10,6 \\
\hline \multirow[t]{4}{*}{ Asa } & MS & 36,6 & 36,3 & 36,9 & 36,6 & 36,6 & 36,6 & 1,4 \\
\hline & PB & 45,2 & 45,3 & 44,9 & 45,3 & 45,2 & 44,9 & 1,8 \\
\hline & EE & 43,1 & 42,9 & 43,3 & 42,8 & 43,1 & 43,3 & 3,3 \\
\hline & MM & 11,7 & 11,8 & 11,8 & 11,9 & 11,7 & 11,8 & 10,4 \\
\hline
\end{tabular}

(1)Médias seguidas de letras diferentes na mesma linha, dentro de cada fator, diferem entre si pelo teste de Tukey a $5 \%$ de probabilidade. 
e menor teor de proteína. Aïn Baziz et al. (1996) observaram que frangos de corte expostos cronicamente ao calor apresentam uma redução proporcional do músculo do peito, ao passo que o músculo da perna é levemente reduzido. Howlider \& Rose (1989) também observaram uma redução no músculo do peito, mas não verificaram alteração na carne escura (coxa), que possui, na sua maioria, fibras vermelhas e enzimas oxidativas (Macari et al., 2002). A redução no crescimento muscular, observada durante exposição ao calor, sugere mudanças no crescimento das fibras, por meio de alterações metabólicas e alterações nas taxas de síntese e degradação protéica, nos diferentes músculos e tipos de fibras. Os teores de proteína bruta utilizados não influenciaram a composição bromatológica de qualquer um dos cortes comerciais estudados (Tabela 4).

O manejo de resíduos merece destaque, uma vez que estudos têm relatado a importância do impacto que agentes, como o nitrogênio, produzem ao meio ambiente (Sloan et al., 1995). Esse impacto pode ser agravado se considerarmos que a exploração avícola brasileira concentra-se em determinadas regiões com alta densidade populacional. Foi observado neste experimento, que a ingestão de nitrogênio diminuiu com a redução do teor de proteína da dieta, uma vez que elas possuem menores concentrações de nitrogênio e o consumo de ração não foi influenciado pelos níveis de proteína bruta da dieta. Com relação à temperatura, observou-se que a ingestão de nitrogênio diminuiu com o aumento da temperatura ambiente em função da redução no consumo de ração.

Os resultados da Tabela 5 revelaram interação significativa entre a temperatura de criação e o teor protéico da ração para retenção, eficiência de retenção e a excreção de nitrogênio. A análise da interação mostra que os teores protéicos não influenciaram a retenção de nitrogênio em aves criadas a 20 ou $25^{\circ} \mathrm{C}$, porém a $32^{\circ} \mathrm{C}$ ocorreu menor retenção de nitrogênio em aves alimentadas com baixa proteína bruta. Assim, dietas com baixa proteína bruta proporcionaram pior eficiência de retenção de nitrogênio nas aves mantidas a $32^{\circ} \mathrm{C}$, ao passo que aves criadas a $20^{\circ} \mathrm{C}$ ou $25^{\circ} \mathrm{C}$ apresentaram melhor eficiência de retenção de nitrogênio quando receberam baixa proteína bruta. A excreção de nitrogênio diminuiu com a redução da proteína dietética somente nas aves submetidas a 20 ou $25^{\circ} \mathrm{C}$, efeito não observado em temperatura ambiente de $32^{\circ} \mathrm{C}$. Esses resultados concordam
Tabela 5. Desdobramento da interação entre temperatura ambiente e teor protéico, na ingestão, retenção, eficiência de retenção e excreção de nitrogênio por frangos de corte de 42 a 49 dias de idade ${ }^{(1)}$.

\begin{tabular}{|c|c|c|c|c|}
\hline \multirow[t]{2}{*}{ Proteína bruta $(\%)$} & \multicolumn{3}{|c|}{ Temperatura ambiente $\left({ }^{\circ} \mathrm{C}\right)$} & \multirow[t]{2}{*}{ Média } \\
\hline & 20 & 25 & 32 & \\
\hline & \multicolumn{3}{|c|}{ Ingestão $\left(\mathrm{g}_{\text {ave }} \mathrm{e}^{-1}\right)$} & \\
\hline 18,0 & 45,7 & 40,1 & 35,3 & $40,4 \mathrm{a}$ \\
\hline 16,5 & 43,3 & 36,7 & 28,8 & $36,3 b$ \\
\hline 15,0 & 39,0 & 35,3 & 28,0 & $34,1 b$ \\
\hline \multirow[t]{2}{*}{ Média } & $42,6 \mathrm{~A}$ & $37,4 \mathrm{~B}$ & $30,7 \mathrm{C}$ & \\
\hline & \multicolumn{3}{|c|}{ Retenção (g ave $\left.{ }^{-1}\right)$} & \\
\hline 18,0 & $31,5 \mathrm{aA}$ & $25,2 \mathrm{aA}$ & $17,8 \mathrm{aB}$ & 24,8 \\
\hline 16,5 & $32,1 \mathrm{aA}$ & $23,3 \mathrm{aB}$ & $14,2 \mathrm{abC}$ & 23,2 \\
\hline 15,0 & $34,6 \mathrm{aA}$ & $26,9 \mathrm{aB}$ & $10,3 \mathrm{bC}$ & 23,9 \\
\hline \multirow[t]{2}{*}{ Média } & 32,7 & 25,1 & 14,1 & \\
\hline & \multicolumn{3}{|c|}{ Eficiência de retenção (\%) } & \\
\hline 18,0 & $69,1 \mathrm{bA}$ & $63,0 \mathrm{bAB}$ & $50,6 \mathrm{aB}$ & 60,8 \\
\hline 16,5 & $74,3 \mathrm{bA}$ & $63,4 \mathrm{bAB}$ & $49,2 \mathrm{aB}$ & 62,3 \\
\hline 15,0 & $88,9 \mathrm{aA}$ & $76,2 \mathrm{aA}$ & $37,3 \mathrm{bB}$ & 67,5 \\
\hline \multirow{2}{*}{ Média } & 77,4 & 67,5 & 45,7 & \\
\hline & \multicolumn{3}{|c|}{ Excreção $\left(g_{\text {ave }}^{-1}\right)$} & \\
\hline 18,0 & $14,1 \mathrm{aA}$ & $14,9 \mathrm{aA}$ & $17,5 \mathrm{aA}$ & 15,5 \\
\hline 16,5 & $11,2 \mathrm{aA}$ & $13,5 \mathrm{abA}$ & $14,6 \mathrm{aA}$ & 13,1 \\
\hline 15,0 & $4,4 \mathrm{bB}$ & $8,4 \mathrm{bB}$ & $17,7 \mathrm{aA}$ & 10,1 \\
\hline Média & 9,9 & 12,2 & 16,6 & \\
\hline
\end{tabular}

(1)Médias seguidas de letras diferentes, maiúsculas nas linhas e minúsculas nas colunas, diferem entre si pelo teste de Tukey a 5\% de probabilidade; os coeficientes de variação para ingestão, retenção, eficiência de retenção e excreção de nitrogênio foram de 8,8, 11,6, 10,7 e 24,4\%, respectivamente.

parcialmente com Blair et al. (1999) e Aletor et al. (2000), que observaram que frangos de corte que receberam baixa proteína bruta apresentam melhor eficiência de retenção e menor excreção de nitrogênio.

\section{Conclusões}

1. A utilização de dietas com baixa proteína, formuladas pelo conceito de proteína ideal, promove pior desempenho para frangos, de 42 a 49 dias de idade, criados em estresse por calor.

2. As dietas com baixa proteína, formuladas pelo conceito de proteína ideal, podem ser utilizadas na alimentação dos frangos criados à temperatura de 20 ou $25^{\circ} \mathrm{C}$, pois não alteram o desempenho e as características de carcaça e diminuem a excreção de nitrogênio.

\section{Agradecimentos}

À Fapesp, pela concessão do auxílio para realização desta pesquisa; à Capes, pela bolsa de estudo concedida a Daniel Emygdio de Faria Filho. 


\section{Referências}

AÏN BAZIZ, H.; GERAERT, P.A.; PADILHA, J.C.F.; GUILLAUMIN, S. Chronic heat exposure enhances fat deposition and modifies muscle and fat partition in broiler carcasses. Poultry Science, v.75, p.505-513, 1996.

ALETOR, V.A.; HAMID, I.I.; NIEB, E.; PFEFFER, E. Low-protein amino acid-supplemented diets in broiler chickens: effects on performance, carcass characteristics, whole-body composition and efficiencies of nutrient utilization. Journal of the Science of Food and Agriculture, v.80, p.547-554, 2000.

ALLEMAN, F.; LECLERCQ, B. Effect of dietary protein and environmental temperature on growth performance and water consumption of male broiler chickens. British Poultry Science, v.38, p.607-610, 1997.

ARAÚJO, L.F. Estudo de diferentes critérios de formulação de rações, com base em perfis de aminoácidos totais e digestíveis para frangos de corte. 2001. 123p. Tese (Doutorado) - Universidade Estadual Paulista, Jaboticabal.

ASSOCIATION OF OFFICIAL ANALYTICAL CHEMISTS AOAC. Official methods of analysis of the Association of Official Analytical Chemists. $14^{\text {th }}$ ed. Washington, DC, 1984. 1094p.

BAKER, D.H.; HAN, Y. Ideal amino acid profile for chicks during the first three weeks posthatching. Poultry Science, v.73, p.14411447, 1994.

BLAIR, R.; JACOB, J.P.; IBRAHIM, S.; WANG, P. A quantitative assessment of reduced protein diets and supplements to improve nitrogen utilization. Journal of Applied Poultry Research, v.8, p.25-47, 1999.

CHENG, T.K.; HAMRE, M.L.; COON, C.N. Effect of constant and cyclic environmental temperatures, dietary protein, and amino acid levels on broiler performance. Journal of Applied Poultry Research, v.8, p.426-439, 1999.

FARIA FILHO, D.E. Efeito de dietas com baixo teor protéico, formuladas usando o conceito de proteína ideal, para frangos de corte criados em temperaturas fria, termoneutra e quente. 2003. 93p. Dissertação (Mestrado) - Universidade Estadual Paulista, Jaboticabal.

GONZALES, E. Ingestão de alimentos: mecanismos regulatórios. In: MACARI, M.; FURLAN, R.L.; GONZALES, E. (Ed.).
Fisiologia aviária aplicada a frangos de corte. Jaboticabal: FUNEP, 2002. p.187-199.

HOWLIDER, M.A.R.; ROSE, S.P. Rearing temperature and the meat yield of broilers. British Poultry Science, v.30, p.61-67, 1989.

KOH, K.; MACLEOD, M.G. Circadian variation in heat production and respiratory quotient in growing broilers maintained at different food intakes and ambient temperatures. British Poultry Science, v.40, p.353-356, 1999.

MACARI, M.; FURLAN, R.L.; GONZALES, E. Fisiologia aviária aplicada a frangos de corte. Jaboticabal: Funep, 2002. 375p.

MACLEOD, M.G. Effects of amino acid balance and energy:protein ratio on energy and nitrogen metabolism in male broiler chickens. British Poultry Science, v.38, p.405-411, 1997.

MUSHARAF, N.A.; LATSHAW, J.D. Heat increment as affected by protein and amino acid nutrition. World's Poultry Science Journal, v.55, p.233-240, 1999.

NIETO, R.; AGUILERA, J.F.; FERNÁNDEZ-FÍGARES, I.; PIETRO, C. Effect of a low protein diet on the energy metabolism of growing chickens. Archives of Animal Nutrition, v.50, p.105119, 1997.

NIETO, R.; PALMER, R.M.; FERNÁNDEZ-FÍGAREZ, I.; PÉREZ, L.; PRIETO, C. Effect of dietary protein quality, feed restriction and short-term fasting on protein synthesis and turnover in tissues of the growing chicken. British Journal of Nutrition, v.72, p.499-507, 1994.

SAS INSTITUTE (Cary, Estados Unidos). SAS user's guide: statistics. Cary, 2002. 466p.

SLOAN, D.R.; HARMS, R.H.; BARNARD, D.; NORDSTEDT, R. Effect of diet on feces composition and the implications on environmental quality. Journal of Applied Poultry Research, v.4, p.379-383, 1995.

TEMIM, S.; CHAGNEAU, A.-M.; PERESSON, R.; TESSERAUD, S. Chronic heat exposure alters protein turnover of three different skeletal muscles in finishing broiler chickens fed 20 or $25 \%$ protein diets. Journal of Nutrition, v.130, p.813819, 2000.

TESSERAUD, S.; PERESSON, R.; CHAGNEAU, A.M. Age-related changes of protein turnover in specific tissues of the chick. Poultry Science, v.75, p.627-631, 1996. 